\title{
Optimal Partition of the Furniture Manufacturing in Croatia
}

\author{
Martina Briš Alić ${ }^{1, *}$ and Martina Harc ${ }^{2}$ \\ ${ }^{1}$ Faculty of Economics in Osijek, J.J. Strossmayer University of Osijek, Gajev trg 7, 31000 Osijek, Croatia \\ E-mail: <mbris@efos.hr> \\ ${ }^{2}$ Croatian Academy of Sciences and Arts, Institute for Scientific and Artistic Work in Osijek, F. Kuhača \\ 29/I, 31000 Osijek, Croatia \\ E-mail: <harcm@hazu.hr>
}

\begin{abstract}
This paper emphasize the clustering of furniture industry as one of the important segments of development strategy of the Croatian economy. Utilizing theoretical and empirical research methods, this study aimed to identify optimal partitioning of seven clusters. In order to identify areas with high concentrations of furniture manufacturers, the fast partitioning algorithm among furniture manufacturers in Croatia - enterprises from class 31.09 Manufacture of other furniture is used. It is important whereas such areas constituted of industry clusters are favourable for targeted cluster-based development. Previous research suggests that companies within clusters achieve higher level of productivity and growth, reach higher levels of innovation and provide favourable environment for entrepreneurship. Higher industry concentration within a specific geographic area offer numerous advantageous resulted from areas abundant with natural resources, human resources, suitable physical and information infrastructure and positive business environment. Using the fast partitioning algorithm, companies from class 31.09 - Manufacture of other furniture are clustered by geographical location (latitude and longitude), the number of employees, average net salary and value added. The results showed that the optimal partitioning of seven clusters is accomplished with observed five variables and that clusters significantly differ between each other according to the observed features.
\end{abstract}

Keywords: cluster analysis, furniture manufacturing, optimal partition, fast partitioning algorithm

Received: December 4, 2017; accepted: July 3, 2018; available online: December 13, 2018

DOI: $10.17535 /$ crorr.2018.0011

\section{Introduction}

As an alternative economic development strategy in the era of globalization, clustering has received much attention in the literature. Industry clusters are known as a catalyst for an

\footnotetext{
* Corresponding author.

http://www.hdoi.hr/crorr-journal
}

(C2018 Croatian Operational Research Society 
economic growth for a very long time. Economists, scientists and policy makers emphasize the important role of industry clusters in a country's growth, the economic development of regions and the growth of enterprises involved in clusters. Clusters are not just companies with similar or complementary interests, competencies and needs to gather around each other. Clusters forms an entire system that consists of manufacturers, suppliers, distributors, research institutions, trained workforce, suitable infrastructure, as well as those who provide a favourable business environment within a cluster. Areas with strong clusters achieve higher level of economic growth, provide more jobs and higher wage, benefit to entrepreneurial and intellectual activity than areas out of the clusters [10]. Advantages of participating within clusters also include enhanced communication and interrelations among companies, improved cooperation, logistics, innovation, and healthy competition leading to increased productivity. Further, companies locating production and services within the cluster gain access to qualified employee, suitable infrastructure and capable suppliers, resulting in reduced costs compared to companies out of clusters [4].

In order to enhance competitiveness in today's knowledge-based and dynamic economy, cluster development initiatives are deployed $[7,10]$. Despite the fact that in last ten years several clusters initiatives have been launched in Croatia, the state of cluster development in Croatia is far from good. According to the Global Competitiveness Report [19] Croatia ranked 124th among 138 economies in terms of cluster development. In 2011, Croatia adopted The strategy for the development of clusters in the Republic of Croatia 2011-2020 which emphasize strengthening the clusters, the knowledge and competences about clusters and clusters members, internationalization of business and export growth, and efficient use of program funds and European Union funds. Croatian wood processing and furniture manufacturing has been developed on high quality forest raw material [13]. The activities of enterprises in this sector are based on the use of forest raw material, traditionally based wood-processing and high quality of human resources [12]. The wood processing industry is an integral part of the Croatian economy. Around $47 \%$ of the Croatian land area is covered by forest. With a strong presence of forests and forest industry, Croatia can potentially benefit from cluster-based economic development. In addition to the above mentioned, in January 2014, the Croatian Ministry of Economy published the Industrial Strategy of the Republic of Croatia 2014-2020 [11] in which the furniture industry was assigned as one of the strategic role, emphasizing the significance of the sub-area C 31.0 - Manufacture of Furniture as Initiators. At its core, all definitions focus on the role of geographic proximity and linkages across activities within clusters. Following Delgado et al. [5], in order to identify and map potential furniture clusters, i.e. areas with high concentrations of these manufacturers, the variables geographical location (latitude and longitude), the number of employees, average net salary and value added are used. The present study contributes to the literature on clustering with an emphasis on furniture industry in Croatia. Moreover, to the best of our knowledge, this paper is the first attempt to determine furniture industry clusters according to geographical location (latitude and longitude), the number of employees, average net salary and value added. The methodology consists of using the fast partitioning algorithm. Following the methodology, it was found that the seven determined clusters significantly differ between each other with regard to all observed variables. 
The rest of this paper is structured as follows. The introduction is followed by the review of related literature defining the concept of cluster. Section 3 presents the data and introduces the methodology applied, whereas Section 4 displays empirical results. Finally, conclusions are given in Section 5.

\section{Literature review - defining the concept of cluster}

An industry cluster refers to a group of companies and institutions located in certain geographic area whose activities are interrelated through value and supply chains, human resources, similar inputs, technology and scientific infrastructure, and complementary products. The reasons why companies gather around each other are similar production interests and needs, mutual success within a certain industry and generation of new business potentials that would not be possible if the companies perform the activities out of clusters or on its own [2]. In explaining agglomeration economies, A. Marshall stressed the benefits that companies can enjoy from locating close to each other, engaged in related activities [14]. According to Marshall, agglomeration economies form, primarily because of the cost-savings and other economic benefits resulting from proximity of companies. Hence, geographic proximity reduces different costs of doing business through input-output linkages, labour market pooling and knowledge spillovers. Transportation costs decrease due to the shorter distance between suppliers, buyers, consumers, and retailers. Labour costs also decrease because a spatial concentration of more businesses attracts a more trained workers and a larger labour supply decrease labour costs. Further, training costs also decrease because facilities and teachers are closer, thereby more students share fixed costs of study. Moreover, Delgado et al. [5], also emphasise the importance of geographic location. According to them, clusters are groups of industries, concentrated within defined geographic area, related by knowledge, skills, inputs, demand, and/or other linkages. The concept of clusters constitutes a number of companies, supporting scientific and research institutions aiming to contribute to competitiveness through various forms of activities and mutual cooperation.

According to the European Commission, clusters positive impact on increasing SMEs competitiveness. The EU spares no efforts in order to make preferable use of clusters for promoting modernisation of regional industry, boosting the growth of SMEs and supporting smart specialisation through cluster policies, cluster initiatives and cluster organisations. Cluster policies refer to set of specific government policy interventions aiming to strengthen existing clusters or to boost the new ones. Further, cluster policies in order to strengthen the competitiveness of enterprises and regions and improve the structure of economic activities aim at linking public, business and scientific research sectors [6]. Cluster initiatives refer to organised efforts aiming to strengthen the competitiveness of a cluster, through practical actions related to the capacity of clusters to self-organise in order to pro-actively shape the future of the cluster. Cluster policies and cluster initiatives follow a bottom-up approach, often managed by cluster organisations and are implemented through a competitive process. Finally, cluster organisations present legal entities aiming to provide specialised and customised business support services by bringing different types of actors together in order to support and facilitate 
the strengthening of collaboration, networking and learning in innovation clusters and act as innovation support providers, [6]. Many authors [4, 8, 16, 17, 24, 25] argued that cluster-based strategies have more than a single, broad aim "to build a cluster". Instead, they have many specific aims, such as boosting innovation and competitiveness, forming new companies, increasing productivity, adding infrastructure improvements, leveraging linkages across economic activities or increasing household income. According to (a subset of Porter's ([16, 17] clusters), companies within regional clusters, due to sharing the common technologies, information, knowledge, skills, infrastructure and similar inputs and by responding to demanding local customers operate more efficiently and innovate faster [5]. Waits [26] also emphasized that clusters, rather than individual enterprises or simple industries, are the source of jobs, income, and export growth. Zheliazkov et al. [27] in their paper identified clusters as patterns for economic transactions and economic outcomes, but also as social systems and multidisciplinary environmental drivers for change. Brown, R. [4] in her paper emphasised four prominent features of an industry cluster captured in a 'clear, concise, and comprehensive definition written by Feser and Renski in 2000': “...industry clusters are groups of businesses and industries related through their presence in a common product chain, dependence on similar labour skills, or utilization of similar or complementary technologies". According to Hagadone and Grala [9], success of industry clusters results from improved cooperation and exchange of knowledge and ideas between companies [23], which leads to increased productivity, reduced costs and improved innovations, at the same time allowing companies to boost competitiveness $[1,2,16]$. Clusters also enable a favourable business environment that supports start-ups and facilitates commercialization of new products and technologies [3]. A positive impact of industry clusters influence to local communities too by increasing economic activities and boosting new employment opportunities [22]. Delgado et al. [5], aiming to create a new set of U.S. Benchmark Cluster Definitions (BCD). Author suggested a set of benchmark cluster definitions that constitutes measures of inter-industry linkages due to co-location patterns, input-output links, and similarities in labour occupations. In order to group industries into a set of defined clusters and to allow clusters to be compared across regions, inter-industry linkages are used. Interindustry linkages are identified through the co-location patterns of industries across regions, or by using the range of national data available across industries. Moreover, Aguilar et al. [2] studied the specific factors affecting clustering in the wood products industry in the Southern United States. The authors concluded that infrastructure, complementarity with other industries, energy costs, cost of primary inputs, costs of land, human resources and linkage with supply chain industries influence the establishment and the development of the successful forest clusters.

\section{Data description and methodology}

In order to identify areas with high concentrations of furniture manufacturers and to constitute furniture industry clusters, the data used in this paper were taken from the business database of Poslovna Hrvatska [18]. The sample includes 326 small, medium and large enterprises classified by activity based on the National Classification of Activities (NKD 2007, OG 58/2007). Each 
enterprise was observed during 2015. According to the NKD 2007, the observed enterprises are included in section C - Manufacturing, division 31 - Manufacture of furniture, class 31.09 Manufacture of other furniture. The listed enterprises perform their core activity mainly in section C - 31 - Manufacture of furniture. The observed units are limited liability and joint stock companies. Financial statements in the form of balance sheets and income statements were available for this research. Due to the absence of any business data, 39 enterprises were excluded from observation. The final sample consisted of 287 enterprises. In order to cluster the observed enterprises, five features were used: geographical location (latitude and longitude), the number of employees, average net salary and value added.

First, the enterprises are described using the data on geographical location ( $x_{\text {_ }} \mathrm{i}, \mathrm{y}$ _ $\mathrm{i}$ ), where abscissae $\mathrm{x}$ i of the points represent the longitudes and the ordinates represent the latitudes.

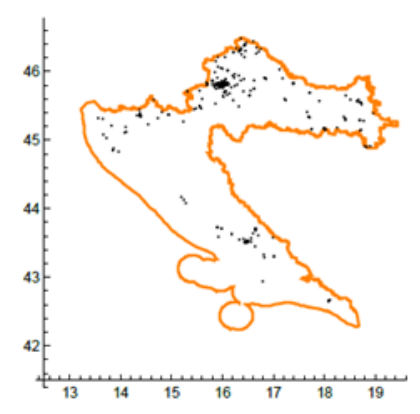

Figure 1: Selected data

On the data set, presented in Figure 1, the fast partitioning algorithm using adaptive Mahalanobis clustering proposed in Morales-Esteban et al. [15] is applied and optimal partitions with $2 \leq \mathrm{k} \leq 11$ clusters are determined. Figure 2 demonstrates optimal partitions with $\mathrm{k}=6,7$ and 8 clusters.
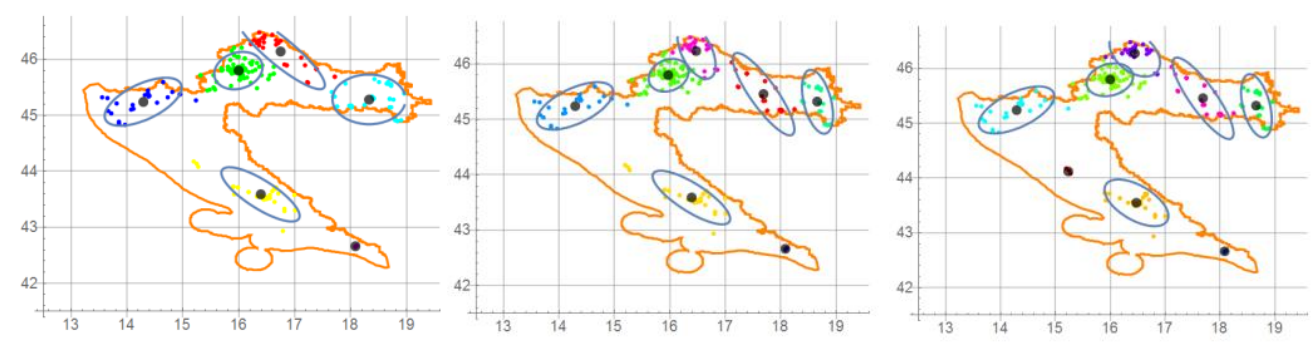

Figure 2: Optimal partitions with $k=6,7$ and 8 clusters

A crucial question is what number of clusters would be optimal for the grouping of the observed data set, i.e. how to choose the partition with the most appropriate number of 
clusters. This question is one of the most complex problems in cluster analysis; it is usually solved by examining different indicators, usually referred to as indexes.

If the number of clusters in which the set should be grouped is not known in advance, the most reasonable way is to try and find the partition consisting of clusters that are internally as compact as possible, and externally as clearly separated from each other as possible. Such a partition is said to have the optimum number of clusters [20].

In each iteration of the algorithm the corresponding clustering validity indexes DaviesBouldin (DB) and Calinski-Harabasz $(\mathrm{CH})$ were calculated:

a) DB index is defined in such a way that internally more compact partition whose clusters are more clearly separated from each other has a lower DB value;

b) $\mathrm{CH}$ index is defined in such a way that internally more compact partition whose clusters are more clearly separated from each other has a higher $\mathrm{CH}$ value.
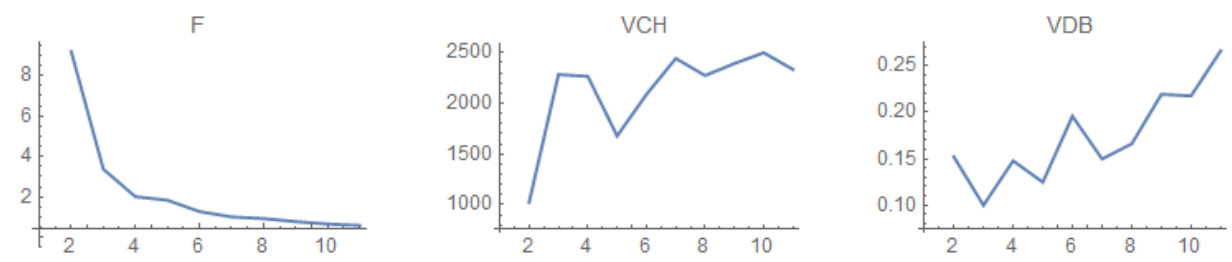

Figure 3: Selection of the partition with the most suitable number of clusters. (a) Objective function values, (b) $C H$ index (c) DB index

As can be seen in Figure 3, CH and DB indexes show that an optimal partition with k $=7$ clusters is the most appropriate partition.

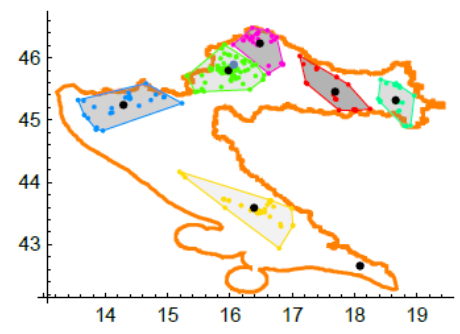

Figure 4: Optimal partition with $k=7$ clusters

In addition to the geographical location, the number of employees, average net salary (in HRK) and value added (in HRK) data are provided to further describe the observed enterprises.

The fast partitioning algorithm proposed in Scitovski \& Scitovski [21] is applied on the data set and optimal partitions with $2 \leq \mathrm{k} \leq 11$ clusters are determined.

As can be seen in Figure 5, in each iteration of the algorithm the corresponding clustering validity indexes Davies-Bouldin (DB) and Calinski-Harabasz (CH) were calculated. 

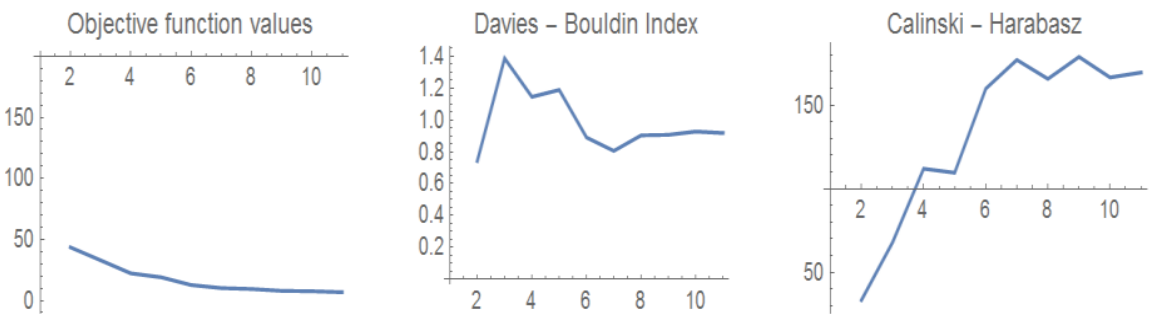

Figure 5: Selection of the partition with the most suitable number of clusters. (a) Objective function values, (b) DB index (c) CH index

Additionally, as presented in Figure 4 and Figure 5, CH and DB indexes show that an optimal partition with $\mathrm{k}=7$ clusters is the most appropriate partition.

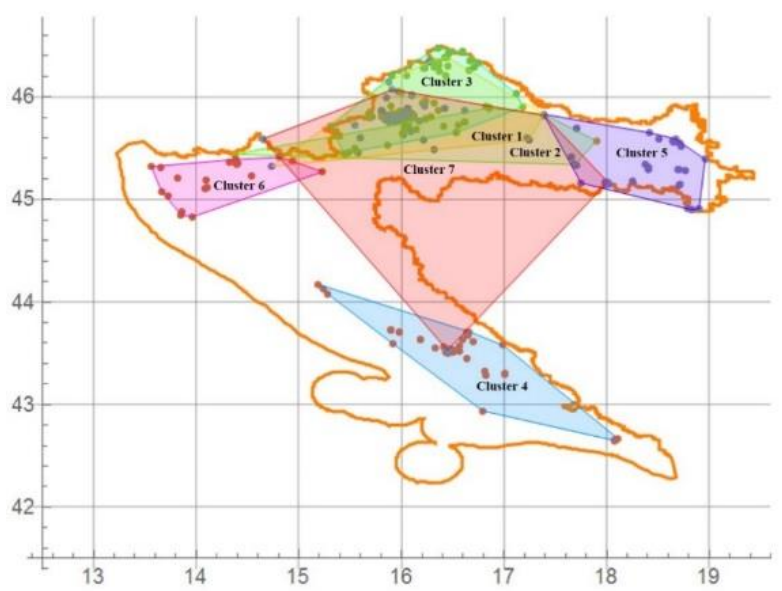

Figure 6: Optimal partition with $k=7$ clusters

As demonstrated in Figure 6, it is evident that results of geographical clusters intersect. This occurs because the algorithm groups the enterprises also by the observed properties, and these observed properties do not have geographical priority.

\section{Validation of results}

As shown in Table 1, 33\% of all enterprises are found in Cluster 3. Cluster 1 and Cluster 4, containing 51 and 46 enterprises respectively, account for $17 \%$ of all enterprises. About $10 \%$ of all enterprises are found in Cluster 5 (39 enterprises), Cluster 6 (26 enterprises) and Cluster 7 (25 enterprises). In terms of the number of enterprises it includes, Cluster 2 is the smallest with only five enterprises. 
140

\begin{tabular}{|l|r|r|r|r|}
\hline & Frequency & Percent & Valid Percent & Cumulative Percent \\
\hline Cluster 1 & 51 & 17.8 & 17.8 & 17.8 \\
\hline Cluster 2 & 5 & 1.7 & 1.7 & 19.5 \\
\hline Cluster 3 & 95 & 33.1 & 33.1 & 52.6 \\
\hline Cluster 4 & 46 & 16.0 & 16.0 & 68.6 \\
\hline Cluster 5 & 39 & 13.6 & 13.6 & 82.2 \\
\hline Cluster 6 & 26 & 9.1 & 9.1 & 91.3 \\
\hline Cluster 7 & 25 & 8.7 & 8.7 & 100.0 \\
\hline Total & 287 & 100.0 & 100.0 & \\
\hline
\end{tabular}

Table 1: Distribution of enterprises by clusters

From Table 2 it is evident that observed enterprises are largely limited liability companies $(99 \%)$, while only three of them are registered as joint-stock companies (Di Klana d.d., Finvest Corp d.d., Spin Valis d.d.).

\begin{tabular}{|l|r|r|r|r|}
\hline & Frequency & Percent & Valid Percent & Cumulative Percent \\
\hline Limited liability company & 284 & 99.0 & 99.0 & 99.0 \\
\hline Joint-stock company & 3 & 1.0 & 1.0 & 100.0 \\
\hline Total & 287 & 100.0 & 100.0 & \\
\hline
\end{tabular}

Table 2: Enterprises by type

Additionally, most of the observed enterprises are small enterprises (275). There are ten medium-sized enterprises and only two are large (Prima commerce d.o.o. and Tvin d.o.o.). Distribution of enterprises into clusters by type of enterprise as presented in Figure 7 shows that two large enterprises are found in Cluster 2. This cluster also includes three medium-sized enterprises, but no small ones. The remaining seven medium-sized enterprises are distributed as follows: Cluster 3 (three enterprises) Cluster 7 (two enterprises), while Cluster 4 and 5 include one medium-sized enterprise each. Figure 7 shows that $33 \%$ of small enterprises are found in Cluster 3. It is interesting that Cluster 1 and 6 are composed exclusively of small enterprises Cluster 1 includes 51 small enterprises while Cluster 6 includes 26 of them. Small enterprises can also be found in Cluster 4 (45 enterprises), Cluster 5 (38 enterprises) and Cluster 7 (23 enterprises). 


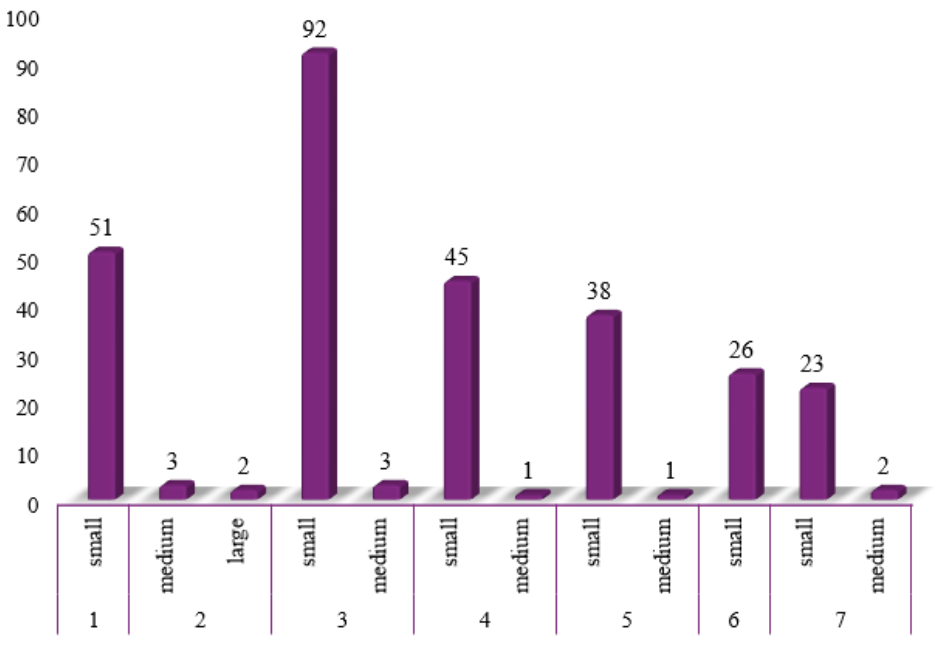

Figure 7: Distribution of enterprises in clusters by type of enterprise

Table 3, as well as Figure 8 indicate that almost $50 \%(47.09 \%)$ of employees are employed in enterprises comprising Cluster 2.

\begin{tabular}{|l|r|r|r|r|r|r|r|}
\hline & $\mathrm{N}$ & Range & Minimum & Maximum & Sum & Percent & Cumulative Percent \\
\hline Cluster 1 & 51 & 5 & 0 & 5 & 18 & 0.36 & 0.36 \\
\hline Cluster 2 & 5 & 495 & 248 & 743 & 2,347 & 47.09 & 47.45 \\
\hline Cluster 3 & 95 & 179 & 1 & 180 & 867 & 17.40 & 64.85 \\
\hline Cluster 4 & 46 & 48 & 0 & 48 & 227 & 4.55 & 69.40 \\
\hline Cluster 5 & 39 & 262 & 0 & 262 & 630 & 12.64 & 82.04 \\
\hline Cluster 6 & 26 & 180 & 0 & 180 & 437 & 8.77 & 90.81 \\
\hline Cluster 7 & 25 & 97 & 1 & 98 & 458 & 9.19 & 100.00 \\
\hline
\end{tabular}

Table 3: Distribution of employees by clusters

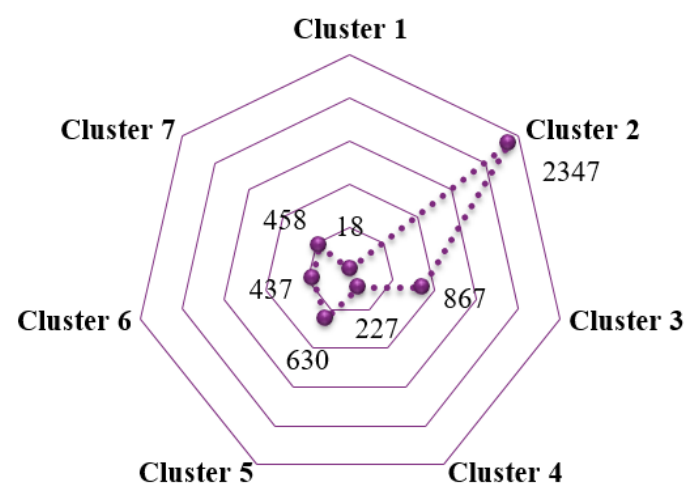

Figure 8: Distribution of employees by clusters 
Table 4 as well as Figure 9 and Figure 10 show that almost $95 \%$ of all enterprises have up to 50 employees, whereas as many as 55 enterprises have no employees.

\begin{tabular}{|l|r|r|r|r|}
\hline & Frequency & Percent & Valid Percent & Cumulative Percent \\
\hline $0-50$ & 272 & 94.8 & 94.8 & 94.8 \\
\hline $50-100$ & 5 & 1.7 & 1.7 & 96.5 \\
\hline $100-150$ & 1 & 0.3 & 0.3 & 96.9 \\
\hline $150-200$ & 3 & 1.0 & 1.0 & 97.9 \\
\hline $200-250$ & 1 & 0.3 & 0.3 & 98.3 \\
\hline $250-300$ & 1 & 0.3 & 0.3 & 98.6 \\
\hline More than 300 & 4 & 1.4 & 1.4 & 100.0 \\
\hline Total & 287 & 100.0 & 100.0 & \\
\hline
\end{tabular}

Table 4: Number of employees

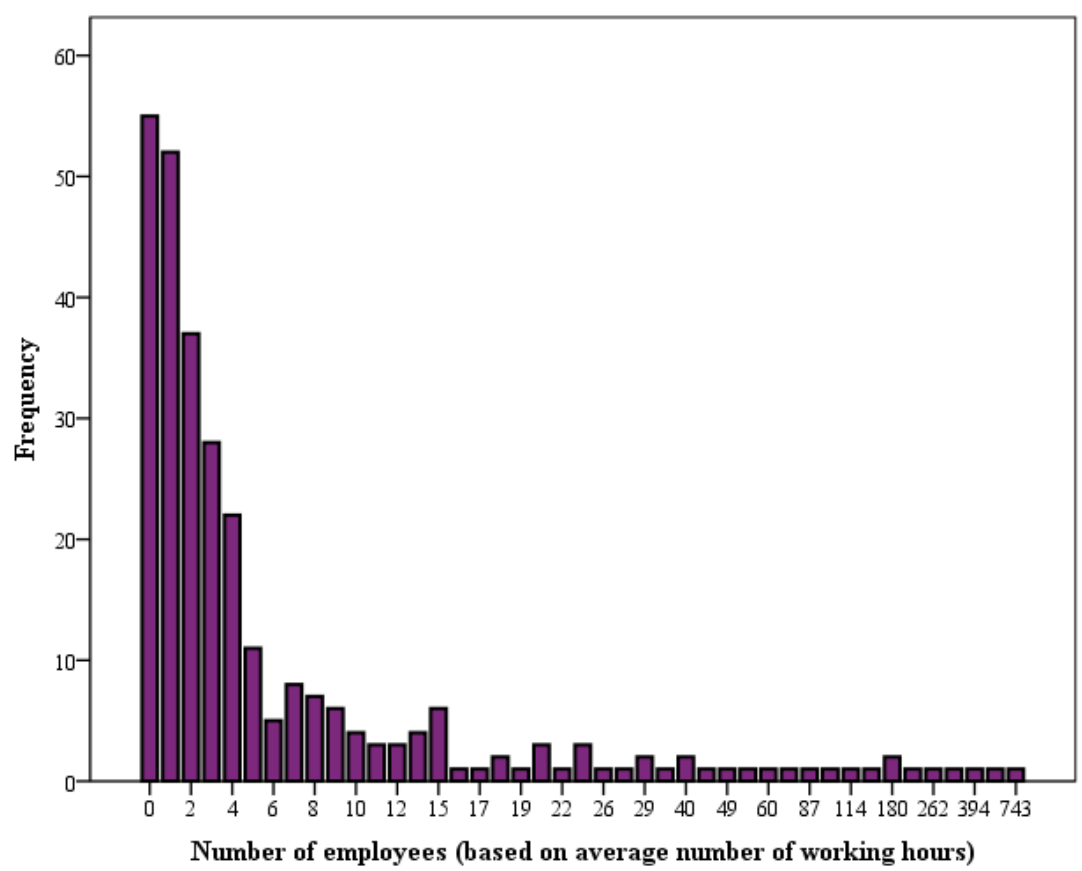

Figure 9: Enterprises by number of employees 


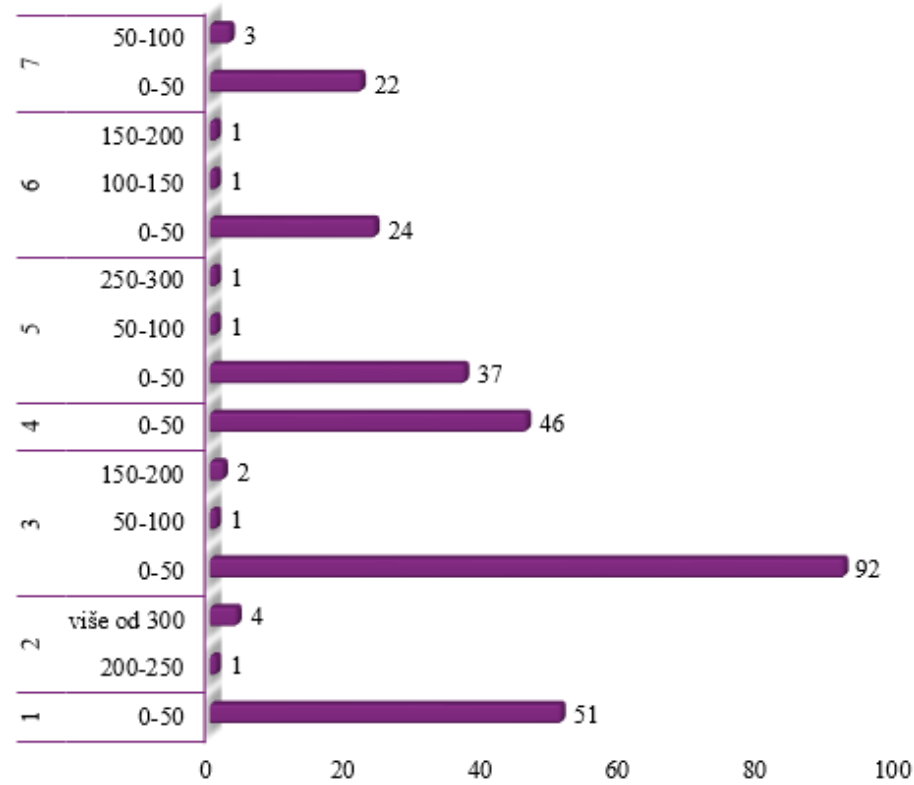

Figure 10: Number of employees by clusters

There are 272 enterprises with up to 50 employees. Figure 11 shows the number of enterprises in terms of the particular class of employee number. Furthermore, 205 enterprises have up to 5 employees.
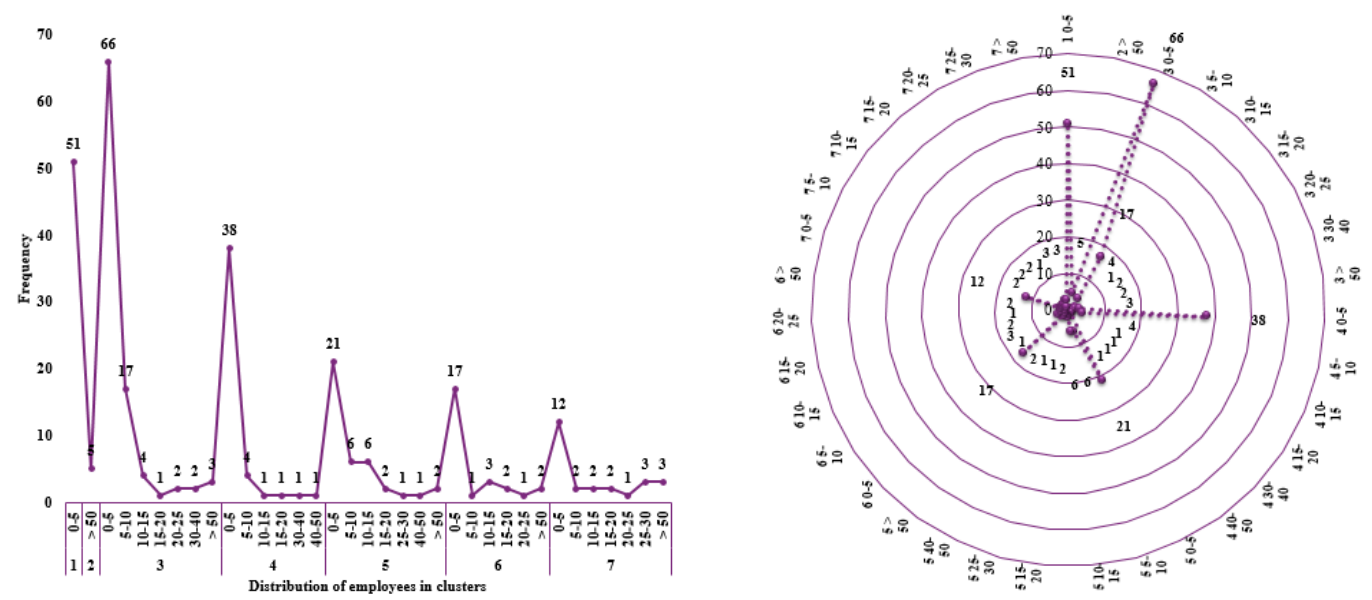

Figure 11: Distribution of number of employees by clusters. (a) Line graph, (b) Radar graph

Table 5 shows that out of 55 enterprises with no employees $70.91 \%$ are in Cluster 1 , which comprises as many as 39 enterprises without employees. On the other hand, in Clusters 2, 3 and 7 there are no enterprises without employees. 


\begin{tabular}{|c|c|c|c|c|c|c|c|}
\hline $\begin{array}{l}\text { Cluster } \\
\text { number }\end{array}$ & $\begin{array}{c}\text { Without/With } \\
\text { employees }\end{array}$ & Frequency & Percent & $\begin{array}{c}\text { Cumulative } \\
\text { Percent }\end{array}$ & $\begin{array}{l}\text { Without } \\
\text { employees }\end{array}$ & Percent & $\begin{array}{c}\text { Cumulative } \\
\text { Percent }\end{array}$ \\
\hline \multirow{2}{*}{$\begin{array}{l}\text { Cluster } \\
1\end{array}$} & without & 39 & 76.5 & 76.5 & \multirow{2}{*}{39} & \multirow{2}{*}{70.91} & \multirow{2}{*}{70.91} \\
\hline & with & 12 & 23.5 & 100.0 & & & \\
\hline $\begin{array}{l}\text { Cluster } \\
2\end{array}$ & with & 5 & 100.0 & 100.0 & 0 & 0.00 & 70.91 \\
\hline $\begin{array}{l}\text { Cluster } \\
3\end{array}$ & with & 95 & 100.0 & 100.0 & 0 & 0.00 & 70.91 \\
\hline \multirow{2}{*}{$\begin{array}{l}\text { Cluster } \\
4\end{array}$} & without & 9 & 19.6 & 19.6 & \multirow{2}{*}{9} & \multirow{2}{*}{16.36} & \multirow{2}{*}{87.27} \\
\hline & with & 37 & 80.4 & 100.0 & & & \\
\hline \multirow{2}{*}{$\begin{array}{l}\text { Cluster } \\
5\end{array}$} & without & 5 & 12.8 & 12.8 & \multirow{2}{*}{5} & \multirow{2}{*}{9.09} & \multirow{2}{*}{96.36} \\
\hline & with & 34 & 87.2 & 100.0 & & & \\
\hline \multirow{2}{*}{$\begin{array}{l}\text { Cluster } \\
6\end{array}$} & without & 2 & 7.7 & 7.7 & \multirow{2}{*}{2} & \multirow{2}{*}{3.64} & \multirow{2}{*}{100.00} \\
\hline & with & 24 & 92.3 & 100.0 & & & \\
\hline $\begin{array}{l}\text { Cluster } \\
7\end{array}$ & with & 25 & 100.0 & 100.0 & 0 & 0.00 & 100.00 \\
\hline
\end{tabular}

Table 5: Enterprises with/without employees by clusters

The highest average net salary (in HRK) in the amount of 5,523.08 ( $\mathrm{SD}=822.97$ ) can be earned in Cluster 7 . Cluster 7 also boasts the highest minimum average net salary, amounting to HRK 4,276.00, and the highest maximum average net salary, amounting to HRK 7,161.00. Next, in terms of the average net salary, leads Cluster 2 with HRK 3,750.60 (SD = 461.18). It is interesting that in Cluster 1 the average net salary amounts to only HRK 181.61 $(\mathrm{SD}=415.03)$. The highest values of standard deviation from the average net salary have been found in Clusters 4, 5, and 6 with the following deviations respectively: HRK 1,437.97, 1,307.31 and $1,130.49$ as shown in Table 6 .

\begin{tabular}{|l|r|r|r|c|r|}
\hline & Frequency & Minimum & Maximum & Mean & Std. Deviation \\
\hline Cluster 1 & 51 & 0 & 1,476 & 181.61 & 415.03 \\
\hline Cluster 2 & 5 & 3,266 & 4,370 & $3,750.60$ & 461.18 \\
\hline Cluster 3 & 95 & 1,663 & 4,226 & $2,841.92$ & 618.93 \\
\hline Cluster 4 & 46 & 0 & 5,395 & $2,375.72$ & $1,437.97$ \\
\hline Cluster 5 & 39 & 0 & 4,271 & $2,343.46$ & $1,130.49$ \\
\hline Cluster 6 & 26 & 0 & 4,393 & $2,823.19$ & $1,307.31$ \\
\hline Cluster 7 & 25 & 4,276 & 7,161 & $5,523.08$ & 822.97 \\
\hline
\end{tabular}

Table 6: Average net salary (in HRK) by clusters 


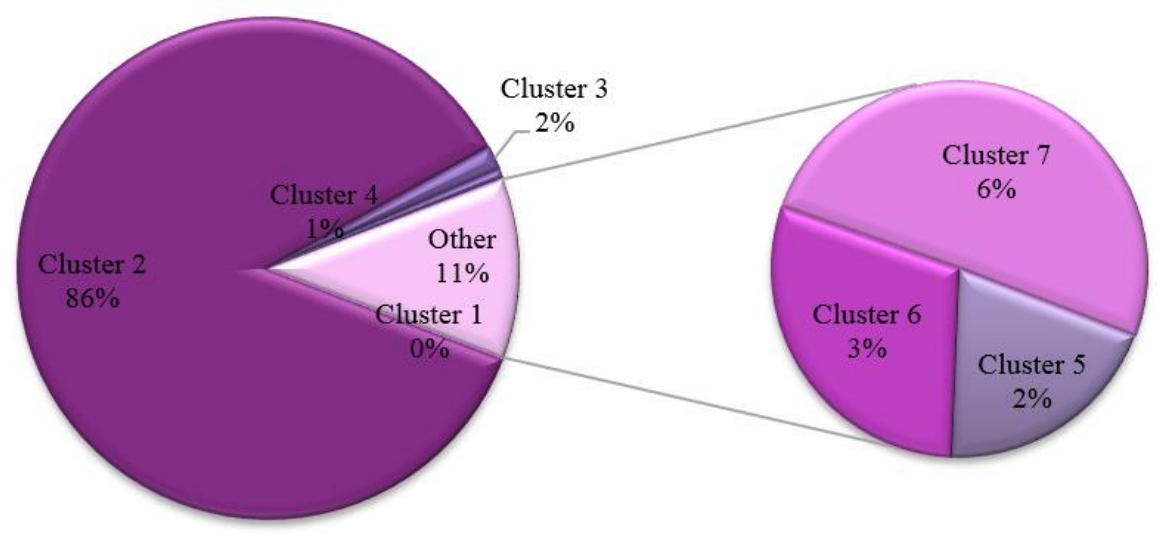

$\square$ Cluster $1 \square$ Cluster $2 \square$ Cluster $3 \square$ Cluster $4 \square$ Cluster $5 \square$ Cluster $6 \square$ Cluster 7

Figure 12: Generated value added by clusters

Figure 12 indicates that $86 \%$ of value added (in HRK) is generated by enterprises in Cluster 2. On average, an enterprise in Cluster 2 generates HRK 38,215,817.40 of value added $(\mathrm{SD}=7,163,189.85)$.

\section{Conclusion}

This paper aimed to determine an optimal partition of the data set. The results show that the optimal partitioning of seven clusters is accomplished with five observed variables. Using the fast partitioning algorithm among furniture manufacturers in Croatia - enterprises from class 31.09 - Manufacture of other furniture, this study aimed to identify areas with high concentrations of furniture manufacturers. It is important whereas such areas constituted of industry clusters are favourable for targeted cluster-based development. Deviations between clusters are emphasized among all observed variables indicating dispersity of results. Cluster 2 with only five companies (three medium and two large), generate $50 \%$ of all employees and $86 \%$ of value added (in HRK) indicating that Cluster 2 is located in appropriate geographical area with well trained workers. Cluster 2 confirms that areas with strong clusters produce more economic growth, more jobs, stronger wage growth and increase entrepreneurial activity.

Contrary, Cluster 1, with 51 small companies, generate $0 \%$ of value added and $77 \%$ of all enterprises have no employees resulting with poor wage salary, meaning that either there is no necessity for developing cluster on this area or targeting development of particular industry cluster is needed on this geographic area. Cluster 7 represent the area with most potential in developing successful industry cluster by boosting innovation and competitiveness, adding infrastructure improvements and forming new companies with increasing productivity. Cluster 7, with 25 companies generates highest average net salary, also and the highest minimum average net salary with no enterprises without employees in this cluster. The huge geographic 
area, easier access to production inputs, well established infrastructure (near highways) and location near institutions with traditionally training of specific human resources are good prerequisites for successful industry cluster development. Although, successful clusters are developing over years, their growth and success is based on advantages of their location near the areas abundant with natural resources, qualified workers, favourable business environment, and suitable infrastructure. Croatian government should better stimulate development and promotion of industry clusters through network of cluster policies, initiatives and organisation. This paper contributes to the literature on clusters in a several ways. First, it promotes and rise public awareness on contribution of the clusters to the economy. Further, our attempt to map clusters according to applied methodology could result with targeting development of successful clusters and within other industries. Third, this paper could foster initiatives for building connections with other clusters in the EU in specific field of furniture production.

\section{Acknowledgements}

The authors would like to thank Professor Rudolf Scitovski (Department of Mathematics, University of Osijek) for his support, very useful comments and suggestions.

\section{References}

[1] Aguilar, F. X. (2008). Effect of centrifugal forces on cluster patterns in the softwood lumber industry of the United States. Forest Science, 54 (2), 242-249.

[2] Aguilar et al. (2009). The status of and Opportunities for business clustering within forest products in the tor U.S. Full Report. http://www.usendowment.org/images/BS_Cluster_Full_report.pdf [Accessed 26/03/2018].

[3] Barkley, D. L. and Henry, M.S. (2005). Targeting industry clusters for regional economic development: an overview of the REDRL approach. Research Report 01-2005-03. Clemson University Regional Economic Development Research Laboratory. http://ageconsearch.umn.edu/bitstream/113803/2/redrl_rpt15.pdf [Accessed 10/07/2016].

[4] Brown, R. (2009). A Practical Guide to Rural, Cluster-Based Economic Development Strategies. University of North Carolina at Chapel Hill. Department of City and Regional Planning. $\quad$ https://cdr.lib.unc.edu/indexablecontent/uuid:e1dc1da9-50d5-4eb8-982d5a8b5ca1ebdb [Accessed 23/03/2018].

[5] Delgado, M., Porter M. E. and Stern, S. (2015). Defining clusters of related industries. Journal of Economic Geography, 16(1), 1-38.

[6] European Commission (2016). Smart Guide to Cluster Policy. Belgium.

[7] European Commission (2017). European Cluster Observatory. https://ec.europa.eu/growth/industry/policy/clusters/observatory_en [Accessed $27 / 03 / 2018]$. 
[8] Feser, E. (2006). Regional Clusters: Theoretical Concepts, Analytical Methods \& Policy Applications. 15th Annual International Seminar in Economic Geography, University of Hannover.

[9] Hagadone, T. A. and Grala, R. K. (2012). Business clusters in Mississippi's forest products industry. Forest Policy and Economics, 20, 16-24.

[10] Harvard Business School. Institute for Strategy and Competitiveness at Harvard Business School. https://www.isc.hbs.edu/competitiveness-economic-development/frameworks-andkey-concepts/Pages/clusters.aspx [Accessed 26/03/2018].

[11] Industrial Strategy of the Republic of Croatia 2014-2020. Official Gazette, 126/15.

[12] Kersan-Škabić, I. (2014). Croatian wood industry - clusters, competitiveness and perspectives of development in the framework of European Union membership. Poslovna Izvrsnost, 8(2), 57-77.

[13] Klarić, K., Motik, D. and Pirc Barčić, A. (2016). Financial aspects of fsc coc wood industry certificate holders. 9th International Scientific Conference WoodEMA 2016 - The path forward for wood products: A global perspective: Baton Rouge, Louisiana, USA, October 5th-8th 2016, 143-148.

[14] Marshall, A. (1920). Principles of Economics. London: MacMillan.

[15] Morales-Esteban, A., Martínez-Álvarez, F., Scitovski, S. and Scitovski, R. (2014). A fast partitioning algorithm using adaptive mahalanobis clustering with application to seismic zoning. Computers \& Geosciences, 72, 132-141.

[16] Porter, M. E. (1990). Competitive Advantage of Nations. New York: Free Press.

[17] Porter, M. E. (1998). Cluster and the New Economic of Competition. Harvard Business Review, 77-90. http://www.csus.edu/indiv/c/chalmersk/econ251fa12/clustersneweconofcompetition.pdf [Accessed 26/03/2018].

[18] Poslovna hrvatska. www.poslovna.hr [Accessed 15/01/2016].

[19] Schwab, K. (2016). World Economic Forum: Global Competitiveness Report 2016-2017. Geneva, Switzerland.

[20] Scitovski, R. and Briš Alić, M. (2016). Grupiranje podataka. Odjel za matematiku, Sveučilište u Osijeku, Osijek.

[21] Scitovski, R. and Scitovski, S. (2013). A fast partitioning algorithm and its application to earthquake investigation. Computers \& Geosciences, 59, 124-131.

[22] Scorsone, E.A. (2002). Industrial Clusters: Enhancing Rural Economies through Business Linkages. The Rural South: Preparing for the Challenges of the 21st Century. Publication No. 23. Southern Rural Development Center, Mississippi State University.

[23] Shields, M., Barkley, D., Emery, M. (2004). Industry Clustering and Industry Targeting. Presented at Industry Targeting Workshop, December 2-3, 2004, Orlando, Florida. Northeast Regional Center for Rural Development, Pennsylvania State University; Regional ProjectNE-1011; and the Rural Poverty Research Institute. http://nercrd.psu.edu/industry_targeting/extensionpapersandslides/indclusterext.shieldsba rkleyemery.pdf. [Accessed 21/03/2016]. 
[24] Smith, R. V. (2003). Industry Cluster Analysis: Inspiring a Common Strategy for Community Development. Central Pennsylvania Workforce Development Corporation. http://citeseerx.ist.psu.edu/viewdoc/download?doi=10.1.1.124.8601\&rep=rep1\&type=pdf [Accessed 26/03/2018].

[25] Stewart, L. S. and Michael I. L. (2003). Best Practices in the Implementation of ClusterFocused Strategy. Office of Economic Development at the Frank Hawkins Kenan Institute of Private Enterprise, University of North Carolina at Chapel Hill. http://www.channelingreality.com/CORE/Workforce_Development/Research_Triangle_C lusters_BestClusterPractices.pdf [Accessed 26/03/2018].

[26] Waits, M. (2000). The added value of the industry cluster approach to economic analysis, strategy development and service delivery. Economic Development Quarterly, 14, 35-50.

[27] Zheliazkov G., Zaimova D., Genchev E. and Toneva, K. (2015). Cluster development in rural areas. https://papers.ssrn.com/sol3/papers.cfm?abstract_id=2703184 [Accessed $27 / 03 / 2018]$. 